\title{
Operational Risk Identification of Electric Power Market Management Committee Based on Intuitionistic Fuzzy FMEA and TOPSIS-GRPM Methods
}

\author{
Jun Dong, Dongxue Wang*, Xihao Dou, Dongran Liu, Shilin Nie, Linpeng Nie \\ School of Economics and Management, North China Electric Power University, Beijing, China \\ Email address: \\ dongjun624@126.com (Jun Dong),18101397665@163.com (Dongxue Wang),2268728128@qq.com (Xihao Dou) \\ ${ }^{*}$ Corresponding author
}

To cite this article:

Jun Dong, Dongxue Wang, Xihao Dou, Dongran Liu, Shilin Nie, Linpeng Nie. Operational Risk Identification of Electric Power Market Management Committee Based on Intuitionistic Fuzzy FMEA and TOPSIS-GRPM Methods. American Journal of Environmental and Resource Economics. Vol. 4, No. 3, 2019, pp. 96-103. doi: 10.11648/j.ajere.20190403.12

Received: May 14, 2019; Accepted: June 13, 2019; Published: July 26, 2019

\begin{abstract}
With the new round of power industry reform in China, the Power Market Management Committee (PMMC) came into being as an autonomous deliberation and coordination body. PMMC plays a bridge role in power market operation, but its operating mechanism is still in the exploratory stage. Research on how to effectively play the functional role in the power market and avoid the effectiveness of the risk is still blank. In order to scientifically identify and evaluate the operational risks of the PMMC and provide guidance and reference for its operation in the electricity market, the article focuses on its responsibilities and procedures, and benchmarks with similar institutions at home and abroad. The traditional FMEA method is applied to analyze the potential risk causes and consequences of PMMC operation, and nine potential risk factors are extracted, then the initial weights of the risk factors were determined by combining the subjective and objective weighting methods with the intuitionistic fuzzy set FMEA method, then the TOPSIS-GRPM method is used to calculate the gray correlation projection closeness, and the final weight of the risk factor is determined. From the evaluation results, it can be seen that the risk of members' composition, professional ability and authority and responsibility allocation are of high level, and need to be focused on prevention and control. Finally, effective measures to avoid and prevent PMMC are put forward to provide reference for the safe and efficient operation of PMMC in China.
\end{abstract}

Keywords: Operational Risk, Risk Model, PMMC, Intuitionistic Fuzzy FMEA Method, TOPSIS-GRPM

\section{Introduction}

The construction of China's electricity market is constantly advancing. In the Opinions on the Establishment and Standardized Operation of Electric Power Trading Institutions issued in 2015 , the state clearly pointed out that the power market management committee composed of power grid enterprises, power generation enterprises, power selling enterprises, power users and so on should be established [1]. Subsequently, each province has set up PMMC and explored its operation mode.

From the operation practice of international mature electricity market, there are market management, recommendation committees or similar functions in each country or region market, and they play an important role in the normal operation of electricity market. Such institutions are usually composed of various market members, dispatching agencies, government departments and so on. Their duties are to negotiate and deal with the important issues of the operation of power trading institutions and market operation. For example, the Nordic Power Trading Agency's User Recommendation Committee, the member committee of PJM in the United States and the Australian Energy Market Committee (AEMC), etc [2].

At present, China's electricity market is in the primary stage of construction, and all kinds of market players play games to seize the reform dividend. This paper makes a comparative analysis of the similarities and differences in the nature and responsibilities of PMMC and similar international organizations. Then, puts forward the necessity of studying 
the operational risk of PMMC. First, PMMC is a self-governing deliberative and coordinating body which is seted up for the reform of the electric power system. It is different from the supervisory authority and has no decision-making power but only the right of suggestion. Second, it is closely related to market participants, trading centers and dispatching agencies. It plays an important role in collecting market participants' opinions, deals with contradictions between market participants, and coordinats the relationship between market participants and government supervision, as well as stabilizs the market and building the electricity market. Third, because its operation mechanism is not perfect, there are many uncertainties in the operation process to be clarified, and the scope of its role is sensitive. Therefore, it is of great significance to effectively identify the potential operational risks for improving the operation efficiency of power market and PMMC.

In recent years, most of the researches on the power market risk are concentrated on the power grid operation, the power market or the power market risk [3-5]. The article [6-7] studies the power transaction management based on the risk management theory and establishes the power industry risk system. Castro M. assessed the risk profile of UK power supply security [8]. Kaijian He proposed a risk value model based on empirical mode decomposition to estimate the downside risk measurement of power market [9]. Wang X establishes a credit risk index system for large users, and evaluates the credit risk of large user transactions [10].

According to the above research, it can be seen that the research methods adopted by scholars, such as stochastic programming, empirical mode decomposition, and risk value model, have higher requirements for historical data quantity and accuracy, and have not yet analyzed the operational risk of PMMC in China. Based on this, the paper obtains PMMC's operational risk index system from two aspects of operation and personnel and organizational structure through FMEA analysis. It uses intuitionistic fuzzy FMEA method and TOPSIS-GRPM method to analyze PMMC's operational risk systematically, determine the importance of risk index, and puts forward effective evasion and preventive measures.

\section{Model of PMMC Operational Risk Analysis}

\subsection{Establishment of PMMC Operational Risk Analysis Model}

Failure Modes and Effect Analysis (FMEA) are used for accident prevention analysis in the protection mechanism system [11]. The FMEA method is used to analyze every potential failure mode, potential failure consequence and potential failure cause of the system. It can effectively identify the risk, and then identify the key elements and weak links of the system. It can provide design basis for improving control measures and emergency management plan before the occurrence of risk accidents.

Through FMEA method, the potential risk modes of PMMC operation are identified, and the causes and consequences of the risks are analyzed. A complete "PMMC operation risk mode analysis table" is established. Then the risk modes under the influence of three risk factors, occurrence (O), severity $(\mathrm{S})$ and detection (D), are evaluated by using intuitionistic fuzzy method. The intuitionistic fuzzy FMEA method can comprehensively reflect the potential causes and possible consequences of risks and evaluate them, so it is suitable for this study.

Technique for Order Preference by Similarity to Ideal Solution (TOPSIS), is a ranking method for comprehensive evaluation of indicators. Firstly, considering the influence of different risk modes, the number of ideal solutions of traditional TOPSIS method will be affected by the number of risk modes, and the calculation of the Euclidean distance between risk modes and positive/negative ideal solutions is heavy [12]. Secondly, when using the traditional grey relational analysis method to analyze specific problems, the method only correlates the feasible scheme with the positive ideal solution, and can't correlate the evaluation scheme with the positive and negative ideal reference sequence at the same time, which leads to the low reliability of the results [13]. Thirdly, in the application of vector projection method, data in high-dimensional space are usually transformed into data in low-dimensional space through projection, which can reduce the computational difficulty. However, the premise of this process is that there is an appropriate and ideal reference object or standard, so it needs to be combined with other methods in the evaluation method to overcome this shortcoming. TOPSIS-Grey Relational Projection Method (TOPSIS-GRPM) can collect the advantages of a single evaluation method [12-13], form a variety of feasible schemes on the basis of effective use of objective sample data, help to compare schemes, make up for the shortcomings of a single evaluation method, and make the evaluation results more scientific and reasonable.

The Operational risk identification of PMMC is a multi-objective decision-making problem. Considering the nature of its work, the index system contains a lot of grey information. Therefore, TOPSIS-GRPM method has good applicability to this study.

\subsection{Risk Recognition and Intuitionistic Fuzzy Assessment}

Firstly, the operational risk model of PMMC is analyzed and its operational risk is extracted. Then the steps for clearly evaluating the necessary information are as follows.

(1) Definition of experts, risk factors and risk models.

The expert evaluation team of PMMC risk is composed of $\mathrm{s}$ experts $E_{k}(k=1,2, \ldots s)$. Considering the difference between expert knowledge system and professional field, experts are divided into s priority levels, and the evaluation information given by experts with higher priority levels is given priority in risk assessment. Assuming that the evaluation information of expert $E_{1}$ has the highest priority level, the evaluation information of expert $E_{s}$ has the lowest priority level.

By focusing on the operation of $m$ potential risk modes 
( $\left.R F_{j}(j=1,2, \ldots n)\right)$ under the influence of $n$ risk factors $\left(F M_{i}(i=1,2, \ldots m)\right)$ and the impact of risk factors on the final risk mode ranking results, linguistic variables are used by expert team to give evaluation information. The evaluation results are transformed into corresponding intuitionistic fuzzy numbers by the rules of transformation of linguistic variables. The intuitionistic fuzzy evaluation matrix of risk mode given by $E_{k}$ is expressed as $\tilde{R}_{k}=\left(\tilde{\alpha}_{i j}^{(\mathrm{k})}\right)_{\mathrm{m} \times \mathrm{n}}$, and the linguistic evaluation information of risk mode $F M_{i}$ under the influence of risk factor $R F_{j}$ can be expressed as $\tilde{\alpha}_{i j}^{(\mathrm{k})}=\left(\mu_{i j}^{(\mathrm{k})}, v_{i j}^{(\mathrm{k})}\right)$. And the weight of risk factor is expressed by intuitionistic fuzzy evaluation matrix $\tilde{W}_{k}=\left(\tilde{\alpha}_{i j}^{(\mathrm{k})}\right)_{1 \times n}$, the linguistic evaluation information of the importance of risk factor $R F_{j}$ is expressed by $\tilde{\alpha}_{j}^{(\mathrm{k})}=\left(\mu_{j}^{(\mathrm{k})}, v_{j}^{(\mathrm{k})}\right)$, the objective and subjective weights of risk factors are expressed by $\omega_{j}^{O}(j=1,2, \ldots n)$ and $\omega_{j}^{S}(j=1,2, \ldots n)$ respectively.

(2) Definition of Intuitionistic Fuzzy Language Variables and Intuitionistic Fuzzy Numbers.

The risk model of the system is unstable in actual operation. It is difficult for experts to give accurate evaluation results when evaluating different risk models under the influence of different risk factors. The difficulty can be reduced by evaluating intuitionistic fuzzy language. According to the following rules, the linguistic evaluation variables given by experts are transformed into intuitionistic fuzzy numbers, as shown in Table 1 [14].

Table 1. Language variables for evaluating risk model weights.

\begin{tabular}{ll}
\hline Linguistic variables & Intuitionistic Fuzzy Numbers \\
\hline Extremely low (EL) & $(0.025,0.900)$ \\
Very low (VL) & $(0.075,0.850)$ \\
Low (L) & $(0.150,0.750)$ \\
Medium low (ML) & $(0.350,0.550)$ \\
Medium (M) & $(0.500,0.500)$ \\
Medium high (MH) & $(0.550,0.350)$ \\
High (H) & $(0.750,0.150)$ \\
Very high (VH) & $(0.850,0.075)$ \\
Extremely high (EH) & $(0.900,0.025)$ \\
\hline
\end{tabular}

Assuming $X$ is a non-empty set, then $\tilde{A}=\left\{<x ; \mu_{\tilde{A}}(x), v_{\tilde{A}}(x)>\mid x \in X\right\}$ is an intuitionistic fuzzy set. Where $\mu_{\tilde{A}}(\mathrm{x})$ is the membership degree of element $x$ in $X$, expressed as $\mu_{\tilde{A}}(x): X \rightarrow[0,1], v_{\tilde{A}}(x)$ is non-membership degree, expressed as $v_{\tilde{A}}(x): X \rightarrow[0,1]$, and satisfies $0 \leq \mu_{\tilde{A}}(x)+v_{\tilde{A}}(x) \leq 1$, abbreviated as $\tilde{\alpha}=(\mu, v)$ is an intuitionistic fuzzy number.

Assuming that $\tilde{\alpha}_{1}=\left(\mu_{1}, v_{1}\right)$ and $\tilde{\alpha}_{2}=\left(\mu_{2}, v_{2}\right)$ are arbitrary two intuitionistic fuzzy numbers, the Hamming distance between $\tilde{\alpha}_{1}$ and $\tilde{\alpha}_{2}$ is expressed by formula (1):

$$
d\left(\tilde{\alpha}_{1}, \tilde{\alpha}_{2}\right)=\frac{1}{2}\left(\left|\mu_{1}-\mu_{2}\right|,\left|v_{1}-v_{2}\right|+\left|\pi_{1}-\pi_{2}\right|\right)
$$

For any intuitionistic fuzzy number $\tilde{\alpha}=(\mu, v)$, its scoring function $s(\tilde{\alpha})$ can be sorted out and transformed by operator of Intuitionistic Fuzzy Prioritized Weighted Averaging (IFPWA). Referring to the revision of scoring function in reference [15], $s(\tilde{\alpha})$ can be expressed by formula (2).

$$
s(\tilde{\alpha})=\frac{1}{2}(1+\mu-v)
$$

(3) Determination of Intuitionistic Fuzzy Comprehensive Evaluation Matrix.

Because the index is divided into cost type and benefit type, the intuitionistic fuzzy number can be transformed by formula (3).

$$
\tilde{\alpha}_{i j}^{*(\mathrm{k})}=\left\{\begin{array}{l}
\tilde{\alpha}_{i j}^{(\mathrm{k})}=\left(\mu_{i j}^{(\mathrm{k})}, v_{i j}^{(\mathrm{k})}\right), j \in \text { Benefit-based risk factors } \\
\operatorname{Neg}\left(\tilde{\alpha}_{i j}^{(\mathrm{k})}\right)=\left(v_{i j}^{(\mathrm{k})}, \mu_{i j}^{(\mathrm{k})}\right), j \in \text { Cost-based risk factors }
\end{array}\right.
$$

In order to ensure the accuracy of the results and determine the priority level of expert evaluation information, the IFPWA operator is applied to this kind of problem in document [16] and the results are satisfactory. The intuitionistic fuzzy number transformed by IFPWA operator can be expressed by formula (4):

$$
\begin{aligned}
& \operatorname{IFPWA}\left(\tilde{\alpha}_{i j}^{*(1)}, \tilde{\alpha}_{i j}^{*(2)}, \ldots \tilde{\alpha}_{i j}^{*(\mathrm{~s})}\right)=\tilde{\alpha}_{i j} \\
& =\left(1-\prod_{k=1}^{s}\left(1-\mu_{i j}^{*(\mathrm{k})}\right)^{\frac{T_{k}}{\sum_{k=1}^{s} T_{k}}}, \prod_{k=1}^{s}\left(v_{i j}^{*(\mathrm{k})}\right)^{\frac{T_{k}}{\sum_{k=1}^{s} T_{k}}}\right)
\end{aligned}
$$

Where $T_{k}=\prod_{t=1}^{k-1} s\left(\alpha_{i j}^{*(\mathrm{k})}\right)(\mathrm{k}=2,3, \ldots \mathrm{s}), T_{1}=1$.

\subsection{Modeling of Units in Virtual Power Plants}

The comprehensive weights of risk factors are determined from both subjective and objective aspects. Then the comprehensive weighting method combined with expert evaluation method and deviation maximization model method is applied to calculate the weights, which can overcome the shortcomings of traditional FMEA method that does not consider the weights of risk factors. The specific steps are as follows:

(1) Assessment of the importance of risk factors.

According to the linguistic variables defined in Table 1, experts give the weight evaluation information of risk factors on the basis of considering the impact of risk factors on the final ranking results of risk models. Then the intuitionistic fuzzy evaluation matrix $\tilde{W}_{\mathrm{k}}=\left(\tilde{\alpha}_{j}^{(\mathrm{k})}\right)_{1 \times n}$ of risk factor weight is obtained, and the weight information of expert risk factor is collated by IFPWA operator, that is: 


$$
\begin{aligned}
& \operatorname{IFPWA}\left(\tilde{\alpha}_{j}^{(1)}, \tilde{\alpha}_{j}^{(2)}, \ldots \tilde{\alpha}_{j}^{(\mathrm{s})}\right)=\tilde{\alpha}_{j} \\
& =\left(1-\prod_{k=1}^{s}\left(1-\mu_{j}^{(\mathrm{k})}\right)^{\frac{T_{k}}{\sum_{k=1}^{s} T_{k}}}, \prod_{k=1}^{s}\left(v_{j}^{(\mathrm{k})}\right)^{\frac{T_{k}}{\sum_{k=1}^{s} T_{k}}}\right)
\end{aligned}
$$

Where $T_{k}=\prod_{t=1}^{k-1} s\left(\alpha_{j}^{(\mathrm{k})}\right)(\mathrm{k}=2,3, \ldots \mathrm{s}), T_{1}=1$.

Then the intuitionistic fuzzy comprehensive evaluation matrix of risk factor weight is obtained and expressed by $\tilde{W}=\left(\tilde{\alpha}_{j}\right)_{1 \times n}$.

(2) Calculation of subjective weights of risk factors.

Combining formula (2), the scoring function value $s\left(\tilde{\alpha}_{j}\right)$ of risk factor weight information is obtained, and then the subjective weight of risk factor is determined, which is expressed by formula (6).

$$
\omega_{j}^{S}=\frac{s\left(\tilde{\alpha}_{j}\right)}{\sum_{j=1}^{n} s\left(\tilde{\alpha}_{j}\right)}
$$

(3) Calculation of objective weights of risk factors.

According to Intuitionistic Fuzzy Comprehensive Evaluation Matrix $\tilde{R}_{k}=\left(\tilde{\alpha}_{i j}^{(\mathrm{k})}\right)_{\mathrm{m} \times \mathrm{n}}$, a model for maximizing the total deviation of risk model evaluation information is constructed, which is expressed by formula (7).

$$
\max \sum_{j=1}^{n} \sum_{i=1}^{m} \sum_{i \neq l} d\left(\tilde{\alpha}_{i j}, \tilde{\alpha}_{l j}\right) \omega_{j}^{O}
$$

Where $\sum_{j=1}^{n}\left(\omega_{j}^{O}\right)^{2}=1, \omega_{j}^{O} \geq 0, j=1,2, \ldots n$

The optimal solution of objective weights of risk factors are normalized by formula (8).

$$
\omega_{j}^{O}=\frac{\sum_{i=1}^{m} \sum_{i \neq l} d\left(\tilde{\alpha}_{i j}, \tilde{\alpha}_{l j}\right)}{\sum_{j=1}^{n} \sum_{i=1}^{m} \sum_{i \neq l} d\left(\tilde{\alpha}_{i j}, \tilde{\alpha}_{l j}\right)}, j=1,2, \ldots \mathrm{n}
$$

(4) Calculation of comprehensive weights of risk factors.

The comprehensive weight can be expressed by formula (9).

$$
\omega_{j}=\gamma_{1} \omega_{j}^{S}+\gamma_{2} \omega_{j}^{O}
$$

Where, $\gamma_{1}$ and $\gamma_{2}$ are the relative importances of subjective and objective weights, and $0 \leq \gamma_{1}, \gamma_{2} \leq 1$.

\subsection{Modeling of Units in Virtual Power Plants}

The comprehensive weights of risk factors are obtained by intuitionistic fuzzy FMEA method, and then the TOPSIS-GRPM method is used to rank the risks finally. The specific steps are as follows:

(1) Determine the definite value of risk factors and the positive and negative ideal solutions of risk model.

The explicit value of the risk model under the influence of risk factors is expressed in $b_{i j}=s\left(\alpha_{i j}\right)$. Considering that the original evaluation data may have different dimensions, the linear proportional method is used to dimensionless process the index values, and the explicit value matrix is expressed by expression (10).

$$
B=\left[\begin{array}{llr}
b_{11} & \cdots & b_{1 n} \\
\vdots & \ddots & \vdots \\
b_{m 1} & \cdots & b_{m n}
\end{array}\right]
$$

Positive and negative ideal solutions are represented by $B^{+}$ and $B^{-}$, respectively, as shown in formula (11).

$$
\begin{aligned}
& B^{+}=\left(b_{01}^{+}, \ldots, b_{0 j}^{+}\right) \\
& B^{-}=\left(b_{01}^{-}, \ldots, b_{0 j}^{-}\right)
\end{aligned}
$$

Where $\left\{\begin{array}{l}b_{0 j}^{+}=\max b_{i j} \\ b_{0 j}^{-}=\min b_{i j}\end{array}\right.$.

(2) Determination of positive and negative ideal grey correlation coefficient matrix.

The sequence of ideal solutions can be expressed as $B^{*}=\left\{b_{01}^{*}, \ldots, b_{0 j}^{*}\right\}$. If the positive ideal solution and the negative ideal solution are taken as two benchmarks respectively, the correlation coefficient of the $i$ risk model under the evaluation index of the $j$ risk factor can be expressed as formula (12):

$$
\delta_{i j}=\frac{\min _{i} \min _{j}\left|b_{0 j}^{*}-b_{i j}\right|+\rho \max _{i} \max _{j}\left|b_{0 j}^{*}-b_{i j}\right|}{\left|b_{0 j}^{*}-b_{i j}\right|+\rho \max _{i} \max _{j}\left|b_{0 j}^{*}-b_{i j}\right|}
$$

Whereas $\rho$ is the resolution coefficient and satisfies $\rho \in[0,1]$. In general, $\rho=0.5$. The grey correlation coefficient matrix with positive ideal solution and negative ideal solution as benchmarks are expressed by expression (13).

$$
R^{ \pm}=\left\{\delta_{i j}^{ \pm}\right\}_{(m+1) \times n}=\left[\begin{array}{ccc}
\delta_{01}^{ \pm} & \cdots & \delta_{0 n}^{ \pm} \\
\delta_{11}^{ \pm} & \cdots & \delta_{1 n}^{ \pm} \\
\vdots & \ddots & \vdots \\
\delta_{m 1}^{ \pm} & \cdots & \delta_{m n}^{ \pm}
\end{array}\right]
$$

Where $\delta_{01}^{+}=\delta_{02}^{+}=\cdots=\delta_{0 n}^{+}=\delta_{01}^{-}=\delta_{02}^{-}=\cdots=\delta_{0 n}^{-}=1$.

(3) Weighted Grey Relational Coefficient Matrix.

From the above steps, the weight matrix of risk factor is $W=\left(\omega_{1}, \ldots \omega_{n}\right)$, and then the weighted grey correlation coefficient matrix of positive ideal and negative ideal can be obtained, as shown in formula (14). 


$$
C^{ \pm}=R^{ \pm} \omega=\left[\begin{array}{ccc}
\omega_{1} & \cdots & \omega_{n} \\
\delta_{11}^{ \pm} \omega_{1} & \cdots & \delta_{1 n}^{ \pm} \omega_{n} \\
\vdots & \ddots & \vdots \\
\delta_{m 1}^{ \pm} \omega_{1} & \cdots & \delta_{m n}^{ \pm} \omega_{n}
\end{array}\right]
$$

(4) Gray Relational Projection Method for Calculating Closeness Degree.

Each risk model can be regarded as a row vector, the risk model is expressed as $f_{i}=\left(\delta_{i 1} \omega_{1}, \ldots, \delta_{i n} \omega_{n}\right)$, and the ideal solution can be expressed as $f_{i}^{*}=\left(\omega_{1}, \ldots, \omega_{n}\right)$.

It is assumed that the angle between the risk model and the ideal solution vector can be expressed as $\theta_{i}$, that is, the grey correlation projection angle. Obviously, the smaller the value of $\theta_{i}$, the greater the projection correlation, and the closer the risk model to the ideal solution. The projection value $f_{i}$ on $f_{i}^{*}$ is expressed by formula (15).

$$
Y_{i}=\left\|f_{i}\right\| \cdot \cos \theta_{i}=\frac{f_{i} \cdot f_{i}^{*}}{\left\|f_{i}^{*}\right\|}=\sum_{j=1}^{n} \delta_{i j} \frac{\omega_{j}^{2}}{\sqrt{\sum_{j=1}^{n} \omega_{j}^{2}}}
$$

Let the weight sequence which can be expressed by $\bar{W}=\left\{\bar{\omega}_{1}, \ldots \bar{\omega}_{n}\right\}$ be a grey relational projection weight vector, where:

$$
\bar{\omega}_{j}=\frac{\omega_{j}^{2}}{\sqrt{\sum_{j=1}^{n} \omega_{j}^{2}}}
$$

Then the grey relational projection values of positive and negative ideal solutions are expressed by formula (17):

$$
Y_{i}^{ \pm}=\sum_{j=1}^{n} \delta_{i j}^{ \pm} \bar{\omega}_{j}
$$

By further calculation, the approximation degree of grey relational projection is obtained, which is expressed by formula (18).

$$
z_{i}=\frac{Y_{i}^{+2}}{Y_{i}^{+2}+Y_{i}^{-2}}
$$

\section{Establishment of PMMC Operational Risk Indicator System}

By the end of 2018, PMMC had been established in 31 provinces/regions in China. Based on the analysis of PMMC's duty orientation requirements, organization plan, working rules and current operation status, this paper constructs the index system from the aspects of internal operation, personnel and organizational structure, and analyses the potential causes of risk and the severity of potential risk consequences. After screening, it mainly includes the following risks:

(1) Aspects of personnel and organizational structure.

Risk of membership, which is likely to occur in determining the number of subjects, the type of membership and the length of service, has an important impact on the fairness of conference resolutions.

Professional competence risk, which is the result of inadequate competence risk, when the professional working group in dealing with various tasks.

Risk of initiative in performance, because PMMC members are part-time and their salaries are still provided by their original units, which results in the risk of members' enthusiasm in performing their functions.

Risk of membership exit, which refers to the risk caused by the absence of a coping mechanism and the absence of provisions on the withdrawal of members in relevant documents.

Distribution Risk of Authority and Responsibility, which refers to the risk caused by improper grasp of the role in exercising power and performing duties.

(2) Aspect of operation.

Autonomy risk, that is, because of the imperfect supervision system of power market and the limited support of PMMC practice, leads to the failure of PMMC autonomy and the risk of poor coordination with government departments.

Risk of deliberation mechanism, that is, the current deliberation mechanism cannot play the role of corresponding functions or deliberation coordination, leading to the failure of PMMC functions.

Coordination risk, which refers to the risk of market disorder caused by the failure to coordinate the interests of various market players.

Risk of Information Leakage, that is, the risk of data leakage in power market is involved in PMMC work.

\section{Application of PMMC Operational Risk Analysis}

\subsection{Identify PMMC Operating Risks}

The operational risk of PMMC is screened by five experts, including personnel, organizational structure and operation. The risk factors are $\mathrm{O}, \mathrm{S}$ and $\mathrm{D}$, and then the potential risk models are analyzed by FMEA method, as shown in Table 2.

Table 2. Analysis of PMMC Potential Risk Model.

\begin{tabular}{lllll}
\hline Risk code & category & Potential risk model & Potential risk consequences & Causes of potential risks \\
\hline FM1 & $\begin{array}{l}\text { Personnel } \\
\text { and }\end{array}$ & Risk of membership & Fairness is questioned & $\begin{array}{l}\text { Unreasonable allocation of members of each } \\
\text { market body }\end{array}$ \\
\hline
\end{tabular}




\begin{tabular}{|c|c|c|c|c|}
\hline Risk code & category & Potential risk model & Potential risk consequences & Causes of potential risks \\
\hline FM2 & organization & $\begin{array}{l}\text { Professional Competence } \\
\text { Risk }\end{array}$ & $\begin{array}{l}\text { Lack of reliability in the outcome of the } \\
\text { proceedings }\end{array}$ & $\begin{array}{l}\text { Lack or inadequacy of professional competence } \\
\text { in electricity market }\end{array}$ \\
\hline FM3 & & $\begin{array}{l}\text { Risk of initiative in } \\
\text { performance }\end{array}$ & Inefficiency of proceedings & $\begin{array}{l}\text { Members are part-time staff without reward and } \\
\text { punishment mechanism }\end{array}$ \\
\hline FM4 & & Risk of membership exit & Incomplete membership & $\begin{array}{l}\text { Lack of coping mechanism for withdrawal of } \\
\text { members }\end{array}$ \\
\hline FM5 & & $\begin{array}{l}\text { Distribution Risk of } \\
\text { Authority and Responsibility }\end{array}$ & $\begin{array}{l}\text { Personnel are unable to exert their } \\
\text { professional advantages or play an } \\
\text { excessive role }\end{array}$ & $\begin{array}{l}\text { The distribution of power and responsibility is } \\
\text { unreasonable or unclear }\end{array}$ \\
\hline FM6 & & Autonomous risk & $\begin{array}{l}\text { Poor coordination with government } \\
\text { departments and coercive interference }\end{array}$ & $\begin{array}{l}\text { China's electricity market supervision system is } \\
\text { not perfect and lacks practical support. }\end{array}$ \\
\hline FM7 & operate & $\begin{array}{l}\text { Risk of deliberation } \\
\text { mechanism }\end{array}$ & Invalidation of PMMC Function & Imperfect or immature Deliberative Mechanism \\
\hline FM8 & & Coordination risk & Market disorder & Unbalanced Interests of Market Subjects \\
\hline FM9 & & Risk of Information Leakage & Loss of interest of market participants & Personnel leak or information system intrusion \\
\hline
\end{tabular}

\subsection{PMMC Operational Risk Assessment}

Nine risks are analyzed by FMEA method, and the processes are as follows:

(1) According to the rules of linguistic variables in Table 1, five experts assessed the operation status of potential operational risks and the importance of risk ranking under the influence of different risk factors. The evaluation information is shown in Table 3.

Table 3. Evaluation information of expert linguistic variables.

\begin{tabular}{|c|c|c|c|c|c|c|c|c|c|c|c|c|c|c|c|}
\hline Risk factor & $\mathbf{O}$ & & & & & $\mathbf{S}$ & & & & & D & & & & \\
\hline Expert & E1 & E2 & E3 & E4 & E5 & E1 & E2 & E3 & E4 & E5 & E1 & E2 & E3 & E4 & E5 \\
\hline Importance of risk factors & EH & $\mathrm{H}$ & $\mathrm{VH}$ & VH & $\mathrm{H}$ & $\mathrm{H}$ & VH & $\mathrm{H}$ & VH & EH & VH & $\mathrm{H}$ & $\mathrm{H}$ & EH & $\mathrm{H}$ \\
\hline FM1 & MH & $\mathrm{H}$ & MH & $\mathrm{VH}$ & ML & $\mathrm{H}$ & $\mathrm{H}$ & $\mathrm{H}$ & MH & $\mathrm{EH}$ & VH & $\mathrm{H}$ & $\mathrm{VH}$ & EH & $\mathrm{H}$ \\
\hline FM2 & VH & $\mathrm{L}$ & $\mathrm{L}$ & EH & VH & EH & EH & EH & $\mathrm{H}$ & $\mathrm{H}$ & $\mathrm{L}$ & VH & VH & ML & $\mathrm{L}$ \\
\hline FM3 & MH & M & M & ML & M & $\mathrm{H}$ & M & MH & $\mathrm{H}$ & VH & M & M & ML & ML & M \\
\hline FM4 & VL & VL & MH & ML & MH & M & MH & MH & $\mathrm{H}$ & $\mathrm{H}$ & M & MH & $\mathrm{L}$ & $\mathrm{MH}$ & VL \\
\hline FM5 & M & MH & M & $\mathrm{MH}$ & M & VH & VH & MH & VH & $\mathrm{H}$ & MH & MH & $\mathrm{H}$ & ML & M \\
\hline FM6 & $\mathrm{M}$ & $\mathrm{H}$ & $\mathrm{H}$ & VH & MH & VH & M & MH & M & $\mathrm{H}$ & VL & VL & VL & $\mathrm{L}$ & VL \\
\hline FM7 & $\mathrm{M}$ & ML & $\mathrm{L}$ & $\mathrm{MH}$ & MH & $\mathrm{VH}$ & $\mathrm{MH}$ & $\mathrm{MH}$ & $\mathrm{MH}$ & $\mathrm{M}$ & ML & VH & $\mathrm{VH}$ & $\mathrm{H}$ & $\mathrm{M}$ \\
\hline FM8 & ML & $\mathrm{M}$ & ML & $\mathrm{M}$ & ML & VH & $\mathrm{VH}$ & $\mathrm{H}$ & VH & $\mathrm{H}$ & ML & $\mathrm{M}$ & ML & ML & ML \\
\hline FM9 & M & ML & MH & $\mathrm{L}$ & ML & MH & M & M & $\mathrm{H}$ & M & ML & ML & ML & M & ML \\
\hline
\end{tabular}

(2) Because $\mathrm{O}, \mathrm{S}$ and $\mathrm{D}$ belong to cost-type risk factors, the intuitionistic fuzzy number of evaluation can be transformed according to formula (3), and the intuitionistic fuzzy evaluation matrix $\tilde{R}_{k}^{*}=\left(\tilde{\alpha}_{i j}^{(\mathrm{k})}\right)_{\mathrm{m} \times \mathrm{n}}$ of risk mode can be obtained. Using IFPWA operator to collate the expert evaluation information, the intuitionistic fuzzy comprehensive evaluation matrix $\tilde{R}=\left(\tilde{\alpha}_{i j}\right)_{\mathrm{m} \times \mathrm{n}}$ of risk mode is obtained, as shown in Table 4.

Table 4. Intuitionistic Fuzzy Comprehensive Evaluation Matrix of Risk Model.

\begin{tabular}{llll}
\hline Risk number & O & S & D \\
\hline FM1 & $(0.298,0.605)$ & $(0.151,0.752)$ & $(0.083,0.840)$ \\
FM2 & $(0.246,0.652)$ & $(0.025,0.900)$ & $(0.538,0.343)$ \\
FM3 & $(0.423,0.562)$ & $(0.229,0.697)$ & $(0.510,0.520)$ \\
FM4 & $(0.738,0.185)$ & $(0.430,0.539)$ & $(0.511,0.490)$ \\
FM5 & $(0.455,0.541)$ & $(0.079,0.847)$ & $(0.339,0.578)$ \\
FM6 & $(0.387,0.586)$ & $(0.152,0.796)$ & $(0.836,0.172)$ \\
FM7 & $(0.539,0.433)$ & $(0.125,0.805)$ & $(0.399,0.501)$ \\
FM8 & $(0.533,0.440)$ & $(0.076,0.849)$ & $(0.537,0.443)$ \\
FM9 & $(0.516,0.500)$ & $(0.399,0.555)$ & $(0.545,0.406)$ \\
\hline
\end{tabular}

(3) Calculation of Risk Factor Weight
According to formula (6-7), the subjective weight vector of risk factor is $\omega_{j}^{S}=\{0.338,0.332,0.330\}$; the objective weight vector is $\omega_{j}^{o}=\{0.309,0.299,0.399\}$. Assuming that the subjective weight and the objective weight are consistent in the importance of risk model evaluation, then $\gamma_{1}=\gamma_{2}=0.5$, so the final comprehensive weight of risk factor is $\omega_{j}=\{0.324,0.316,0.360\}$.

(4) According to formula (10), the definite value matrix $B$ of expert evaluation can be obtained.

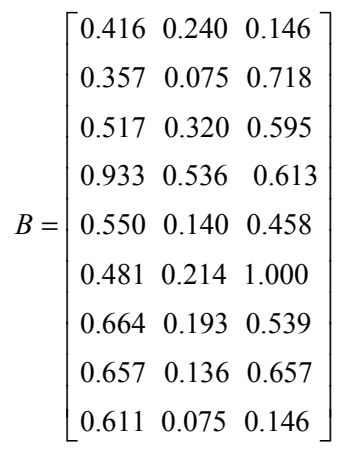


Combined with Table 4, the ideal solutions of each failure mode can be obtained, as shown in Table 5.

Table 5. Ideal Solution of Fault Mode.

\begin{tabular}{llll}
\hline & O & S & D \\
\hline Positive ideal solution & 0.933 & 0.536 & 1.000 \\
Negative ideal solution & 0.357 & 0.075 & 0.146 \\
\hline
\end{tabular}

(5) According to the formula (12-13), the grey correlation coefficient matrix is obtained, which is the benchmark of positive ideal solution and negative ideal solution.

$$
\begin{aligned}
& R^{+}=\left\{\delta_{i j}^{+}\right\}_{(m+1) \times n}=\left[\begin{array}{ccc}
1.000 & 1.000 & 1.000 \\
0.879 & 0.721 & 1.000 \\
1.000 & 1.000 & 0.427 \\
0.727 & 0.635 & 0.487 \\
0.426 & 0.481 & 0.478 \\
0.689 & 0.868 & 0.578 \\
0.775 & 0.716 & 0.333 \\
0.582 & 0.783 & 0.521 \\
0.587 & 0.875 & 0.455 \\
0.627 & 0.497 & 0.442
\end{array}\right] \\
& R^{-}=\left\{\delta_{i j}^{-}\right\}_{(m+1) \times n}=\left[\begin{array}{ccc}
1.000 & 1.000 & 1.000 \\
0.452 & 0.591 & 0.330 \\
0.426 & 0.481 & 0.602 \\
0.507 & 0.664 & 0.513 \\
1.000 & 1.000 & 0.525 \\
0.527 & 0.519 & 0.441 \\
0.486 & 0.594 & 1.000 \\
0.614 & 0.555 & 0.481 \\
0.607 & 0.516 & 0.555 \\
0.570 & 0.938 & 0.575
\end{array}\right]
\end{aligned}
$$

(6) Computation of Closeness Degree of Grey Relational Projection

According to formula (14-17), the ideal solution is $f_{i}^{*}=(0.324,0.316,0.360)$, the weight vector of grey projection is $\bar{\omega}_{j}=(0.314,0.299,0.388)$, the grey correlation projection value of positive ideal solution is $\left(Y_{i}^{+}\right)^{T}=[0.880,0.779,0.608,0.463,0.700,0.587,0.619,0.623,0.517]$, and the grey correlation projection value of negative ideal solution

is

$\left(Y_{i}^{-}\right)^{T}=[0.448,0.511,0.557,0.817,0.492,0.718,0.545,0.560,0.683]$. Finally, through formula (18), the grey relational projection pasting progress is calculated to be $\left(z_{i}\right)^{\mathrm{T}}=[0.794,0.699,0.544,0.243,0.670,0.400,0.563,0.553,0.364]$, which is the grey relational projection value of each risk model. The sorted results are shown in Table 6.

From the data in the table, FM1, FM2 and FM5 are the closest to the ideal solution, which shows that the risk of membership, professional ability and authority and responsibility allocation have great impact on the operation and construction of PMMC, and need to be focused on prevention and control. As members mainly come from various market entities, including power generation enterprises, electricity sales enterprises, power grid enterprises, users and third-party organizations, how to determine the types of members, the number of members and the length of service of members have important impacts on the fairness of conference resolutions and the balanced development of the market. As for the risk of professional competence, because the reform of electricity market is still in its infancy, the shortage of professionals engaged in electricity market may affect the effectiveness of professional teams and have an important impact on the operational effectiveness of PMMC. As for the risk of authority and responsibility allocation, PMMC is an autonomous deliberative and coordinating body. Only when its powers and responsibilities are clear, can it provide organizational guarantee for the efficient operation of PMMC.

Table 6. Final evaluation and ranking.

\begin{tabular}{llll}
\hline Risk code & Risk model & $\boldsymbol{z}_{\boldsymbol{i}}$ & Result ranking \\
\hline FM1 & Membership risk & 0.794 & 1 \\
FM2 & Professional Competence Risk & 0.699 & 2 \\
FM3 & Positive Risk in Performance & 0.544 & 6 \\
FM4 & Members' Access and Exit Risk & 0.243 & 9 \\
FM5 & Distribution Risk of Authority and Responsibility & 0.670 & 3 \\
FM6 & Autonomous risk & 0.400 & 7 \\
FM7 & Risk of deliberation mechanism & 0.563 & 4 \\
FM8 & Coordination risk & 0.553 & 5 \\
FM9 & Risk of Information Leakage & 0.364 & 8 \\
\hline
\end{tabular}

\section{Conclusion}

The intuitionistic fuzzy FMEA and TOPSIS-GRPM are used to analyze the operational risk of PMMC. On the one hand, traditional FMEA risk assessment methods are widely used in researches, but there are still many shortcomings. This paper combines the FMEA method with the intuitionistic fuzzy theory, which makes up for the 
shortcoming of the subjective calculation results of traditional FMEA. On the other hand, the method of TOPSIS-GRPM is introduced into the final evaluation of PMMC operational risk factors. Taking the common characteristics of PMMC in China as the research object, the FMEA potential risk model of PMMC operational risk is analyzed from two aspects, and nine potential risk factors are extracted. Finally, the paper combines the advantages of the above methods, and takes into account the different knowledge background and experience of experts in the specific evaluation. Therefore, the IFPWA operator is used to transform the evaluation information of experts, and the importance of each potential risk is ranked. The results show that the risk of membership, professional competence, authority and responsibility allocation have great impacts on the operation and construction of PMMC. The operational risk of PMMC should be taken seriously to provide reference for improving and strengthening the efficiency of PMMC.

\section{References}

[1] Development and Reform Commission, Energy Bureau. Opinions on the Establishment and Standardized Operation of Electric Power Trading Institutions [R]. 2015.

[2] MacGill I. Electricity market design for facilitating the integration of wind energy: Experience and prospects with the Australian National Electricity Market[J]. Energy Policy, 2010, 38 (7): 3180-3191.

[3] Wang Zhaocong, Ma Qian. Investment Risk Analysis of Power Grid Enterprises Based on Analytic Hierarchy Process and Monte Carlo Method [J]. Smart Power, 2018, 46 (07): $42-48+74$.

[4] Wang Zhe. Electricity retailer market operation mode and risk research [D]. Southeast University, 2017.

[5] Cheng Cheer. Market Risk Research in Electricity Market Environment [J]. Mechatronics Information, 2018 (6).

[6] Bao Jie, Xie Qin, Wang Zhongrong and Li Yan. Power market transaction management based on risk management theory $[\mathrm{J}]$. Electrical era, 2017 (11): 20-21.
[7] Dabbagh S R, Sheikh-El-Eslami M K. Risk assessment of virtual power plants offering in energy and reserve markets $[\mathrm{J}]$. IEEE Transactions on Power Systems, 2016, 31 (5): 3572-3582.

[8] Castro M. Assessing the risk profile to security of supply in the electricity market of Great Britain[J]. Energy Policy, 2017, 111: 148-156.

[9] He K, Wang H, Du J, et al. Forecasting Electricity Market Risk Using Empirical Mode Decomposition (EMD)—Based Multiscale Methodology [J]. Energies, 2016, 9 (11): 931.

[10] Wang X, Lai C, Yu D, et al. Credit Risk Management and Evaluation of Large User Transaction in Electricity Market[C]//2018 IEEE 3rd Advanced Information Technology, Electronic and Automation Control Conference (IAEAC). IEEE, 2018: 49-53.

[11] Jing Shuwei, Wen Zhifang, Yan Junai. Risk Identification of Coal Mining Enterprises Based on FMEA and Fuzzy VIKOR [J]. Industrial Engineering, 2017, 20 (02): 91-98.

[12] Van der Cheng, Du Mingyue. Dynamic comprehensive evaluation of technological innovation capability of high-tech industry based on TOPSIS grey relational projection method from the perspective of Beijing-Tianjin-Hebei integration [J]. Operational research and management, 2017, 26 (07): 154-163.

[13] Ke Hongfa, Chen Yongguang, Xia Bin. A multi-objective decision-making algorithm based on projection approaching ideal grey correlation [J]. Journal of Electronics, 2007 (09): 1757-1761.

[14] Wang Rui, Zhu Jianghong, Li Yanlai. An improved FMEA risk assessment method based on intuitionistic fuzzy MULTIMOORA [J]. Computer Integrated Manufacturing System, 2018, 24 (02): 290-301.

[15] Xu Yongjie, Sun Tao, Li Dengfeng. Intuitionistic Fuzzy POWA Operator and Its Application in Multi-criteria Decision Making [J]. Control and Decision Making, 2011, 26 (01): 129-132.

[16] Yu D. Intuitionistic fuzzy prioritized operators and their application in multi-criteria group decision making[J]. Technological and Economic Development of Economy, 2013, 19 (1): 1-21. 